\title{
Evaluation of Carbon Dioxide Emissions from Container Ports
}

\author{
Yutaka Watanabe *
}

\begin{abstract}
This paper introduces a macro traffic flow model of carbon dioxide emissions from container ports. As long as both the throughput and the transshipment rate of the port are available, any port in the world can use it to estimate emissions. Initially, two Japanese container ports are used as reference points to derive the equivalent units of carbon dioxide per TEU for application to other ports. Then macro traffic flows within a container port are defined. Finally, carbon dioxide emissions from different container ports are estimated using the macro estimation procedure introduced in this paper. The results of trial estimations for selected ports among different countries highlight that the impacts of container ports on global warming are serious. This issue will be intensified if competition is increased by the larger container ports aspiring to be international mega hubs.
\end{abstract}

Keywords: Global Warming, Container Ports, Carbon Dioxide Emissions, Environmental Responsibility, Transshipment.

\section{INTRODUCTION}

In recent years, port responsibility for global warming has begun to be recognized in some developed countries although most research efforts have been limited to local environmental issues. Meanwhile, larger container ports have been rapidly expanding in many countries; these ports are also competing against each other to be recognized as international mega hub ports in the near future. There is no doubt that these ports emit greater amounts of carbon dioxide emissions, thereby accelerating global warming. To recognize the consequences and port responsibility, global research is urgently required to gauge emissions from container ports in different countries soon. This is the aim of this paper.

There are clearly two general directions for estimating carbon dioxide emissions from container ports. One direction is to make a case study of a local port, which provides precise information to provide a micro estimation. However, there are only a few ports that are likely to be cooperative because, if included in the study, ports run the risk of revealing confidential customer information. Therefore, it will be impossible to study all container ports in the world. The other direction is to find

- Associate Professor, Tokyo University of Marine Science and Technology, 2-1-6 Etchujima, Koto-ku, Tokyo 135-8533, E-mail: ywatana@e.kaiyodai.ac.jp 
equivalent units of carbon dioxide for container traffic flows in a port by which the emissions from any port in the world can be approximately estimate. Thus, this paper explores the latter direction referring to a pilot research undertaken by the author.

Initially, two Japanese container ports are used as reference points to derive the equivalent units of carbon dioxide per TEU for application to other ports. Then macro traffic flows within a container port are defined. Finally, carbon dioxide emissions from container ports among different countries are estimated using the macroestimation procedure introduced in this paper.

\section{RESPONSIBILITY OF PORTS FOR GLOBAL WARMING PROBLEM}

The problem of global warming caused by carbon dioxide emissions from industries has been widely recognized since the Kyoto Protocol was approved. The responsibility of ports for emissions has already drawn considerable public attention in some countries. Some port authorities in California have, for example, begun to impose penalties on shipping lines for emissions (Cauthen, 2003). Reportedly, in New York, emissions from ferry traffic have caused serious air pollution (Long and Shore, 2003). In Germany, incentive programs to reduce emissions from ships have been planned by environmental NGOs (Bahike, 2003). In Japan, carbon dioxide emissions from road transportation were measured in port areas using experimental measures based on the number of truck movements (Watanabe and Oikawa, 2003). This literature highlights how seriously ports and related transportation modes pollute the air. However, efforts to mitigate the missions have been motivated mainly by the desire of domestic public interests to preserve the local environment in their countries rather than by any adverse international reaction.

Not only are domestic transport modes involved but also international port users, notably those engaged in intermodal container transportation. Some major hub ports for example, have benefited from Transshipments of foreign containers. These ports have an international responsibility for the global environment. Therefore, carbon dioxide emissions from these ports must be analyzed and compared internationally. This is the thrust of this paper because such comparisons have not been undertaken in previous research on ports. To internationally compare the environmental responsibility of container ports, this paper introduces a macro estimation procedure by which the throughput and the Transshipment rates in a port can be converted to carbon dioxide emissions. 


\section{MACRO ESTIMATION OF CARBON DIOXIDE EMISSIONS FROM CONTAINER PORTS}

\section{System Model of Carbon Dioxide Emissions from Ports}

The system of measuring carbon dioxide emissions in ports has been already structured by pilot research undertaken by the author as shown in Figure 1 (Sakai, Watanabe and Oikawa, 2003). Precise measurement can be achieved if the micro or the hybrid estimation is applied together with detailed port information. Unfortunately, terminal operators regard such information as confidential, and therefore it is difficult to establish the precise measurement for ports for all countries. This is because there has been no research conducted by which carbon dioxide emissions from ports are compared between different countries.

Figure 1. System model of evaluating carbon dioxide emissions from ports[5]

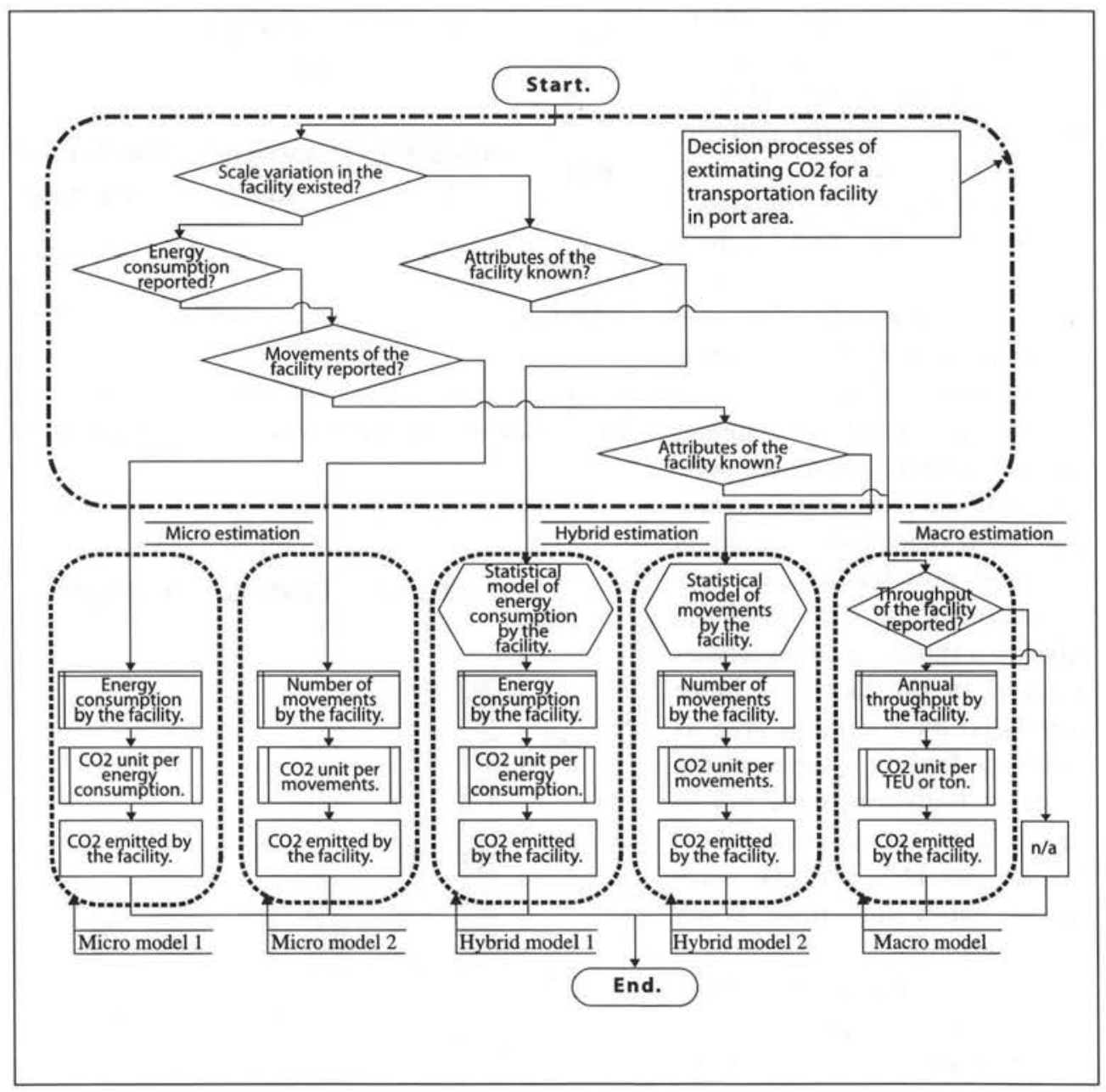


On the other hand, operations and facilities of container ports, (i.e., container ships, cargo-handling equipment and trucks have been internationally standardized since the beginning of containerization. Therefore, it is appropriate to suppose that the amount of carbon dioxide emissions from a container port fluctuates in proportion to the volume of container traffic in the port, which is popularly counted in twenty-foot equivalent units (TEUs). The availability of this information enables us to overcome the problem of finding information for precise measurement. If there is a container port from which sufficient data on running the micro or the hybrid estimation are available, equivalent units of carbon dioxide per TEU can be derived from the measurement and the volume of port throughput. Once such equivalent units are found, can be applied in the macro estimation by which carbon dioxide emissions from any ports can be universally estimated. This consequence is shown in Figure 1 (see bottom right).

\section{Equivalent Units of Carbon Dioxide for Throughputs in Container Ports}

To verify the above hypothesis of the macro estimation, this paper refers to two Japanese container ports for which carbon dioxide emissions have been previously measured by the micro and hybrid estimations shown in Figure 1 (Sakai and Watanabe, 2003) In the analysis of the figure, carbon dioxide emissions have been evaluated for container ships and tugboats on the inner harbor, cargo-handling equipment in the container terminals and land transportation in the port districts. These two ports have very different characteristics from each other. One is a small container port located in a less populated local area, and the other is a typical major gateway located in the heart of huge populated metropolitan area as shown in Table 1. Despite of the contrast between these ports, equivalent units of carbon dioxide per TEU of these ports are absolutely similar as shown in Figure 2.

Figure 2, together with Table 1 , proves that the equivalent units of carbon dioxide per TEU in the
Table 1. Comparison between Port of Yokohama and Port of Shimizu

\begin{tabular}{c|r|r|c}
\hline Port & $\begin{array}{c}\text { Throughput } \\
\text { (TEU) }\end{array}$ & $\begin{array}{c}\text { Transshipment } \\
\text { Rate }\end{array}$ & $\begin{array}{c}\text { Population of } \\
\text { Hinterland }\end{array}$ \\
\hline \hline Yokahama & $2,303,781$ & 0.112 & 40 million \\
\hline Shimizu & 400,154 & 0.056 & 0.7 million \\
\hline
\end{tabular}

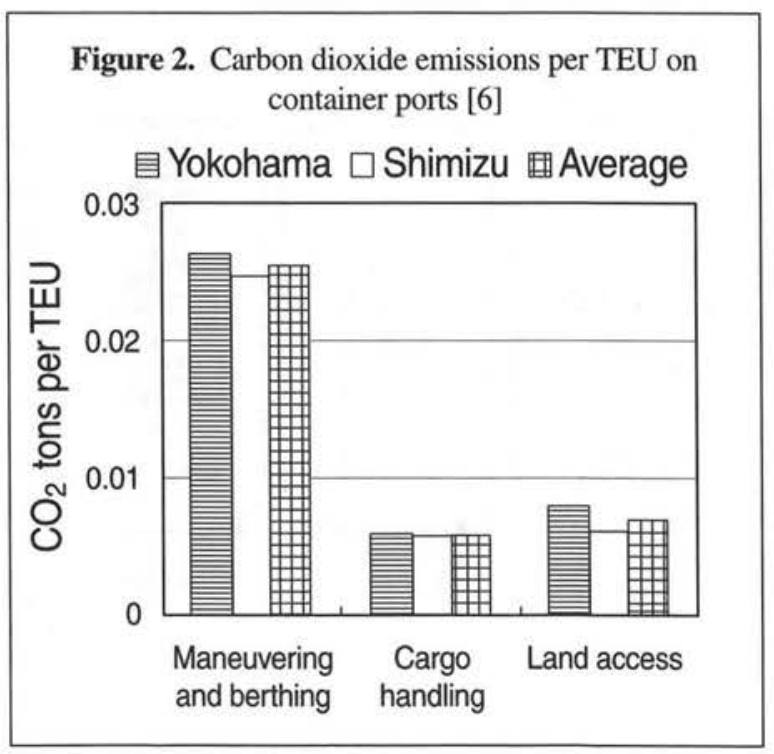


figure can be utilized for other container ports using the macro estimation shown in Figure 1 without suffering from any fatal error.

\section{TRAFFIC FLOW MODEL OF CARBON DIOXIDE EMISSIONS FROM CONTAINER PORTS}

\section{Macro Traffic Flow in Container Ports}

To use the equivalent units of carbon dioxide, macro traffic flows of containers in a port have to be defined as incoming or outgoing containers measured in TEUs. Figure 3 shows a practical outline of the definition on the macro traffic flows. Each traffic flow in the figure can be described as follows:

$$
\begin{aligned}
E= & \text { Outgoing containers by } \\
& \text { container ships, } \\
I= & \text { Incoming containers by }
\end{aligned}
$$

Figure3. Macro traffic flows of container ports container ships,

$E d=$ Incoming containers by land transportation,

$I d=$ Outgoing containers by land transportation,

$T=$ Transshipment containers,

where $E+I$ is generally regarded as a throughput of a container port. Statistically, one Transshipment container has to be counted twice in a port because of the custom's procedures. Therefore, the Transshipment rate of a port can be defined as follows:

$$
\begin{aligned}
t & =\text { Transshipment rate, } \\
& =2 T /(E+I) .
\end{aligned}
$$

The transshipment rate is also a common port statistic, which is reported by international journals as frequently as the throughput is done. Both are essential to running the macro estimation. 


\section{Formulation of Carbon Dioxide Emissions by Traffic Flow Model}

Each traffic flow in Figure 3 is related each other as follows:

$E=T+E d$,

$I=T+I d$.

Hence

$$
\begin{aligned}
E+I & =2 T+E d+I d, \\
& =t(E+I)+E d+I d, \\
E d+I d & =(1-t)(E+I),
\end{aligned}
$$

where $E d+I d$ is equivalent to the volume of containers moved by land transport, which can be calculated from the throughput and the transshipment rates. Obviously, the volume of total container traffic to and from a container port can be descried as follows:

$$
\begin{aligned}
V & =\text { Volume of Total Container Traffic, } \\
& =E+I+E d+I d,
\end{aligned}
$$

thus

$$
\begin{aligned}
& E+I=V /(2-t), \\
& E d+I d=(1-t) V /(2-t) .
\end{aligned}
$$

In container ports, handling containers is one source of carbon dioxide emissions. As offshore gantry cranes use electricity, yard cranes and other terminal cargo handling equipment cause the emissions directly emitted from ports because they are powered by diesel engines. Hence, the number of the cargo-handling units related to the emissions is defined as follows:

Number of Cargo Handling $=2 E d+2 I d+2 T$,

$$
\begin{aligned}
& =(2-t)(E+I), \\
& =V .
\end{aligned}
$$

Finally, carbon dioxide emissions from a container port are defined as follows:

$$
\begin{aligned}
C O 2 & =\{\alpha+\beta(2-t)+\gamma(1-t)\}(E+I), \\
& =\{\alpha(2-t)+\beta+\gamma(1-t) /(2-t)\} V,
\end{aligned}
$$

where

$\mathrm{CO} 2$ = Carbon Dioxide Emissions from Container Port,

$\alpha=$ Equivalent Unit of Carbon Dioxide for Inner Harbor Water Transportation, 
$\beta=$ Equivalent Unit of Carbon Dioxide for Cargo Handling on Container Terminal,

$\gamma=$ Equivalent Unit of Carbon Dioxide for Land Transportation in Port District.

Thus, carbon dioxide emissions from any container port can be estimated by the equation 8 and the equivalent units shown in Figure 2 provided both the throughput and transshipment rate of the port are simultaneously available. It is also interesting to realize that the environmental impact of the transshipment rate can be simulated by equation 9 if $\mathrm{V}$ is set as constant.

\section{INTERNATIONAL COMPARISON OF CARBON DIOXIDE EMISSIONS FROM CONTAINER PORTS}

\section{Throughput and Transshipment Rate of Container Ports}

Information on throughputs and transshipment rates of container ports is generally provided in most countries because basic statistics are needed to plan port development. Therefore, there are many publications, which can be easily referred. This paper, for example, uses an international journal for cargo handling industries, which provides the required information on over one hundred container ports (Case, 2002). Table 2 shows examples from the journal referred to in this paper; there are many other possibilities that could have been used.

\section{Results of Macro Estimation of Carbon Dioxide Emissions}

Figure 4 shows results of the macro estimation explained in Sections III and IV in which carbon dioxide emissions from the ports listed in Table 2 have been calculated using the average equivalent units shown in Figure 2 and applying them in equations 8 and the equation 9. Surprisingly, container ports emit large amounts of carbon dioxide emissions a year. The figure shows that total emissions from all the ports can reach one million tons a year even though there are only seven ports included in the estimation. Needless to say, the total amount of emissions from all container ports in the world could be large and a serious contributor to global warming. Larger container ports have 
a disproportionate impact. For instance, the Port of Busanthe world's third largest port in 2001, emits 0.3 million tons of carbon dioxide emissions a year.

There is another serious problem evident in Figure 4. If the transshipment rate of container ports increases rapidly, carbon dioxide emissions will expand, although the total volume of container traffic of the ports may not increase. This also has serious consequences for global warming because there is a tendency for larger container ports to become an international mega hub port calling eagerly for transshipment cargoes. Furthermore, competition among mega-port has been fierce in recent years. Their increased throughput must accelerate global warming if appropriate international responsibility for their carbon dioxide emissions is not accepted.

\section{CONCLUSION}

This paper has derived the macro traffic flow model of carbon dioxide emissions from two Japanese container ports. Provided a port's throughput and the transshipment rate are available, the model can be applied to any port in the world. The results of trial estimations for selected ports in different countries reveal the seriousness of the impact of container ports on global warming. This situation will worsen if the recent competition among the larger container ports is intensified because these ports are seeking to be ranked as international container hubs. To mitigate this outcome an urgent international agreement is required, which imposes on container ports reasonable compensation for their carbon dioxide emissions.

Since this paper's efforts and results are, however, limited it would be inappropriate to consider seeking compensation from the countries that own the ports. A fairer proposition would be to charge ports on the basis of the density of carbon dioxide emissions using either a per capita basis or in terms of the country's gross domestic product. Then, we will be able to distinguish which countries are more responsible for carbon dioxide emissions. This compensatory aspect should be the focus of future research. 


\section{REFERENCES}

Bahlke, Christian (2003). "Blue Angel Award for environment-conscious ship operation", Proceedings of International Conference on Ship and Shipping Research, Spain, Barcelona, pp. 583-590.

Cass, Sidney (2002). “Top 100 Container Ports", Cargo Systems July 2002, A Cargo Systems Supplement.

Cauthen, Sue (2003). "Green regulations tough on US ports", Cargo Systems September 2003, pp. 46-47.

Long, Russell and Teri Shore (2003). "Air pollution from passenger ferries in New York Harbor", Bluewater Network, New York. http://www.bluewaternetwork.org

Sakai, Hiroshi. Yutaka Watanabe and Toshinori Oikawa (2003). "Environmental impact of carbon dioxide emissions on intermodal container ports", Proceedings of International Conference on Ship and Shipping Research, Barcelona, pp.549-561.

Sakai, Hiroshi and Yutaka Watanabe (2003). "The estimation model of carbon dioxide emission on the container terminal", Japan Industrial Management Association, Journal of Japan Industrial Management Association, Japan, Tokyo, 7p.

Watanabe, Yutaka and Toshinori Oikawa (2003). "Environmental impact of intermodal transportation by trucks on ports", Proceedings of International Association of Maritime Economists Annual Conference, Busan, pp. 864-873. 